Article

\title{
An ASIC-Based Miniaturized System for Online Multi-Measurand Monitoring of Lithium-Ion Batteries
}

\author{
Giuseppe Manfredini ${ }^{1,2, *(1)}$, Andrea Ria ${ }^{1,2}$ (), Paolo Bruschi ${ }^{1}$, Luca Gerevini ${ }^{2,3}{ }^{(D}$, Michele Vitelli ${ }^{2}$, \\ Mario Molinara $^{3}$ (i) and Massimo Piotto ${ }^{1}$ (D) \\ 1 Department of Information Engineering, University of Pisa, 56122 Pisa, Italy; \\ andrea.ria@ing.unipi.it or andrea.ria@sensichips.com (A.R.); paolo.bruschi@unipi.it (P.B.); \\ massimo.piotto@unipi.it (M.P.) \\ 2 Sensichips srl, 04011 Aprilia, Italy; luca.gerevini@sensichips.com or luca.gerevini@unicas.it (L.G.); \\ michele.vitelli@sensichips.com (M.V.) \\ 3 Department of Electrical and Information Engineering, University of Cassino and Southern Lazio, \\ 03043 Cassino, Italy; m.molinara@unicas.it \\ * Correspondence: giuseppe.manfredini@phd.unipi.it or giuseppe.manfredini@sensichips.com
}

check for updates

Citation: Manfredini, G.; Ria, A.; Bruschi, P.; Gerevini, L.; Vitelli, M.; Molinara, M.; Piotto, M. An ASIC-Based Miniaturized System for Online Multi-Measurand Monitoring of Lithium-Ion Batteries. Batteries 2021, 7, 45. https://doi.org/10.3390/ batteries 7030045

Academic Editor: Mauro

Francesco Sgroi

Received: 27 May 2021

Accepted: 1 July 2021

Published: 5 July 2021

Publisher's Note: MDPI stays neutral with regard to jurisdictional claims in published maps and institutional affiliations.

Copyright: (c) 2021 by the authors. Licensee MDPI, Basel, Switzerland. This article is an open access article distributed under the terms and conditions of the Creative Commons Attribution (CC BY) license (https:/ / creativecommons.org/licenses/by/ $4.0 /$ )

\begin{abstract}
To better asses the ageing and to reduce the hazards involved in the use of LithiumIon Batteries, multi-measurand monitoring units and strategies are urged. In this paper, a Cell Management Unit, based on the SENSIPLUS chip, a recently introduced multichannel, multi-mode sensor interface, is described. SENSIPLUS is a single System on a Chip combined with a reduced number of external components, resulting in a highly miniaturized device, built on $20 \times 8 \mathrm{~mm}^{2}$ printed circuit board. Thanks to SENSIPLUS' versatility, the proposed system is capable of performing direct measurements (EIS, cell voltage) on the cell it is applied to, and reading different kinds of sensors. The SENSIPLUS versatile digital communication interface, combined with a digital isolator, enable connection of several devices to a single bus for parallel monitoring a large number of cells connected in series. Experiments performed by connecting the proposed system to a commercial Lithium-Ion Battery and to capacitive and resistive sensors are described. In particular, the capability of measuring the cell internal impedance with a resolution of $120 \mu \Omega$ is demonstrated.
\end{abstract}

Keywords: lithium-ion batteries; System on a Chip; Cell Management Unit; electrochemical impedance spectroscopy; multi-measurand acquisition system

\section{Introduction}

In recent years, the use of Lithium-Ion Batteries (LIBs) has been continuously increasing and nowadays LIBs are the battery of choice for many applications, including low power devices, such as portable electronics and high-energy systems like Electric Vehicles (EVs) [1-3]. LIBs are also considered a viable solution for large-scale energy storage and back-up power sources for the grid [4]. The success of LIBs is due to their high specific energy and specific power with respect to conventional lead-acid, nickel-cadmium, and nickel-metal hydride batteries [1-5]. However, the use of LIBs also poses safety concerns due to the instability of its electrochemical system that can lead to thermal runaway resulting in fire or explosion [6]. For these reasons, the operating conditions must be continuously monitored and controlled to maintain the battery in a safe and reliable operation mode. This task is performed by the Battery Management System (BMS), a complex electronic unit with many features, including battery data acquisition, modelling and state estimation, cell balancing, thermal management, charge and discharge control, safety monitoring, fault diagnostics, and health management [7-10]. To meet the voltage and capacity requirements, battery packs are usually organized in one or more modules, each consisting of numerous cells that are connected in series and/or parallel. In this situation, maintaining the individual cell within a defined set of operating parameters is becoming a great challenge. BMS 
for small EVs or appliances are based on a centralized architecture with voltage, current, and temperature measuring circuits and other functional sub-systems placed on a single controller unit. This solution proved inadequate for multi-module LIBs, thus, an advanced BMS with a distributed architecture was proposed [11,12]. In this case, the cells are divided into groups, each monitored by a slave electronic unit that sends its data to a master control unit through an electrically isolated serial bus. A modularized BMS is usually more efficient than a traditional one in controlling batteries for high-energy applications, where a large number of cells is present. However, the performance of the whole battery pack strongly depends on characteristics of the so-called weak cells that hold less capacity and charge or discharge faster than other cell. The weakest cells must be identified, monitored, and controlled during the operating life in order to maximize the efficiency and fully exploit the capacity of the battery. For this reason, the concept of smart cell, where the monitoring and controlling functions of the BMS are decentralized at the individual cell level, has been proposed [13]. In this case, each cell is equipped with a dedicated electronic circuit, named Cell Management Unit (CMU), that can monitor and control the cell parameters and communicate with the other devices. Furthermore, LIBs are complex electrochemical systems with many interacting processes, with different and often unpredictable ageing mechanisms that over time contribute to loss of its capacity. Therefore, the accurate prediction of battery state is an active research topic and it is better performed with the acquisition of multiple electrical and physical parameters in operating conditions $[14,15]$.

In this work, we propose a multi-measurand CMU based on the SENSIPLUS platform, a programmable mixed-signal integrated circuit being developed by SENSICHIPS s.r.l. [16] in cooperation with the Department of Information Engineering of the University of Pisa. The SENSIPLUS is a multi-input, multi-mode sensor interface, suitable for performing Electrochemical Impedance Spectroscopy (EIS) with high accuracy in the "online" configuration, meaning that the cell does not need to be disconnected during the measurement.

EIS is one of the most relevant characterization and diagnostic techniques for batteries because it provides information about the internal LIB components by means of impedance measurement at various frequencies through external electrodes [17-19]. A large number of works, dealing with EIS measurements performed on batteries by means of relatively large and expensive laboratory instrumentation, have been published [20,21]. Different solutions to perform EIS in operating conditions have been proposed in the literature [22]. Most of them modify circuits that are already present in the battery and load management system (e.g., DC/DC and DC / AC converters, charge balancing system) to produce the stimulus for the EIS and use off-the-shelf components for detecting the response $[23,24]$. This strategy strongly depends on the existing hardware and cannot be shared with other different battery systems. The use of separate, purposely-build electronic circuits optimized for online EIS allows obtaining compact hardware that can be adapted to different battery systems $[25,26]$. However, the solutions proposed so far lack versatility because the integrated circuits are designed for EIS only and cannot be used to acquire other relevant electrical and physical parameters. In particular, there is a great effort in developing new types of electrodes and electrolytes to improve the performances of batteries that are becoming even more complex electrochemical system $[3,27,28]$. For this reason, the evaluation of battery State of Health $(\mathrm{SoH})$ require the acquisition of multiple parameters. The main advantage of the solution proposed in this work is the possibility to perform a large number of measurements on the cell using a single, very miniaturized device. The chip also includes versatile communication functions enabling connections of different devices for monitoring of multi-cell battery packs.

This work is organized as follows: in Section 2, the SENSIPLUS chip is introduced together with the Printed Circuit Board (PCB) that supports the SENSIPLUS and forms the proposed CMU; in the same section, two examples of external sensors that can be managed by the CMU are also described. In Section 3, the results of measurements performed with the proposed system are presented; these measurements include both tests involving the 
sensors and EIS acquisitions performed on a commercial LiPo (Lithium-ion Polymer) cell. Finally, in Section 4, conclusions are drawn.

\section{System Architecture}

A typical configuration of a battery pack made up of some cells connected in series is shown in Figure 1A. Communication between the CMUs and a microcontroller is implemented with an $\mathrm{I}^{2} \mathrm{C}$ protocol or a SENSICHIPS proprietary single-wire protocol, named SENSIBUS. The SENSIBUS connection among different battery cells results is easier than a standard one due to the lower number of wires required and, consequently, the number of possible fault and the wiring complexity. Each cell is monitored by means of a dedicated $\mathrm{CMU}$, whose schematic block diagram is presented in Figure 1B. The CMU includes the SENSIPLUS chip, a DC-balanced, AC unbalanced Wheatstone bridge, and the digital isolator that are described in the following sections.

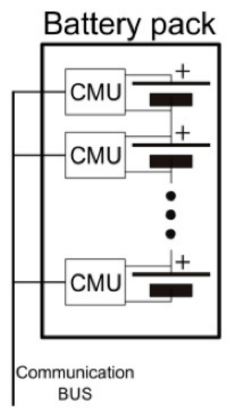

A)

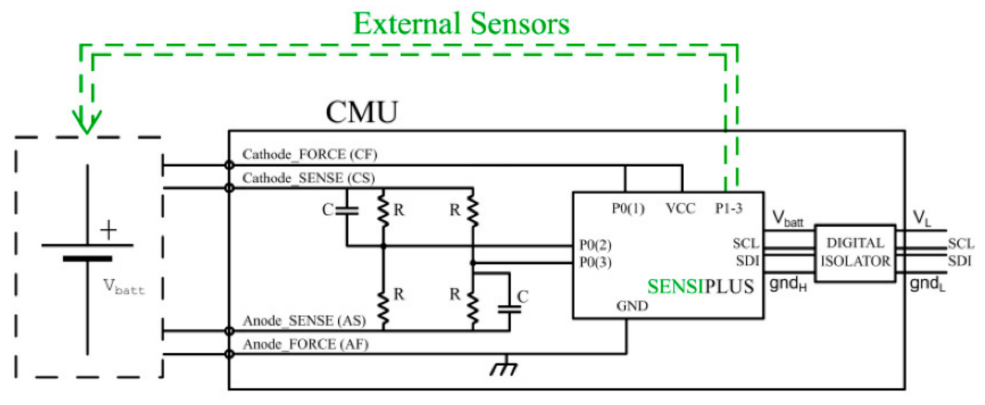

B)

Figure 1. (A) Typical battery pack scenario; (B) schematic block of CMU connection.

An example of the cell measurement setup is shown in Figure 2. The system includes the custom PCB (named CMU in the rest of the paper), two external sensors applied to the cell electrodes (External Electrode Sensor-EES), and the external sensors applied to the body of the cell (External Body Sensor-EBS).

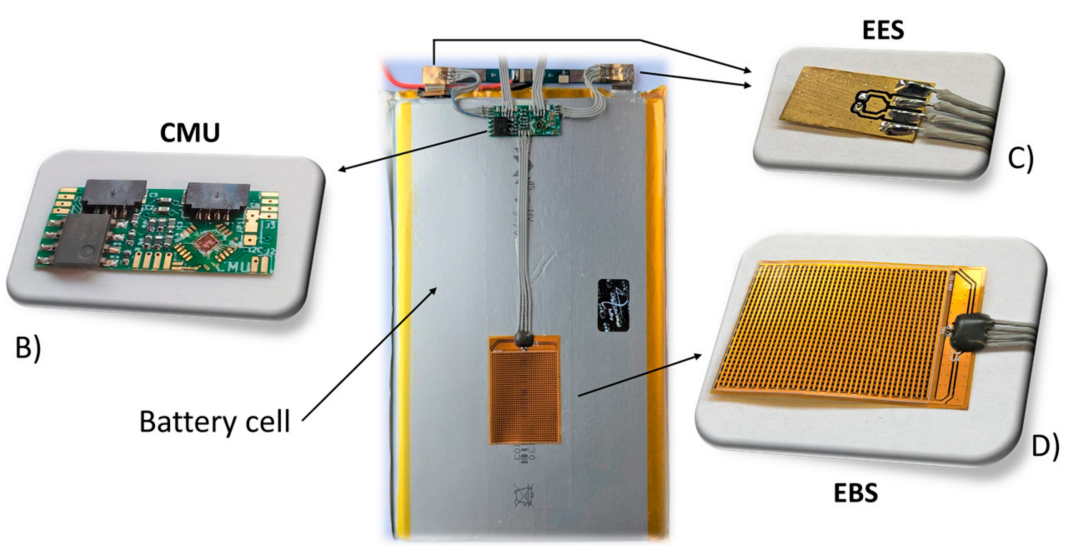

A)

Figure 2. (A) Photo of the assembled system with a focus on: (B) CMU board; (C) External Electrode Sensor (EES); (D) External Body Sensor (EBS).

\subsection{CMU Description}

The CMU, whose schematic view is shown in Figure 1, consists of a Printed Circuit Board of size $20 \times 8 \mathrm{~mm}^{2}$. A photograph of the CMU is shown in in Figure 3, where the digital isolator and the connectors to the communication bus are indicated. External sensors and the cell under test are connected to the CMU by wires directly soldered to proper pads of the PCB. The SENSIPLUS chip is directly glued to the CMU board as a naked die, while bonding between the chip and PCB pads is accomplished by means of wire 
bonding. Bonding wires are protected by a resin ring that leaves the central part of the chip uncovered, where on-chip sensors are placed. A magnification of the CMU area where the chip is placed is shown in Figure 3.

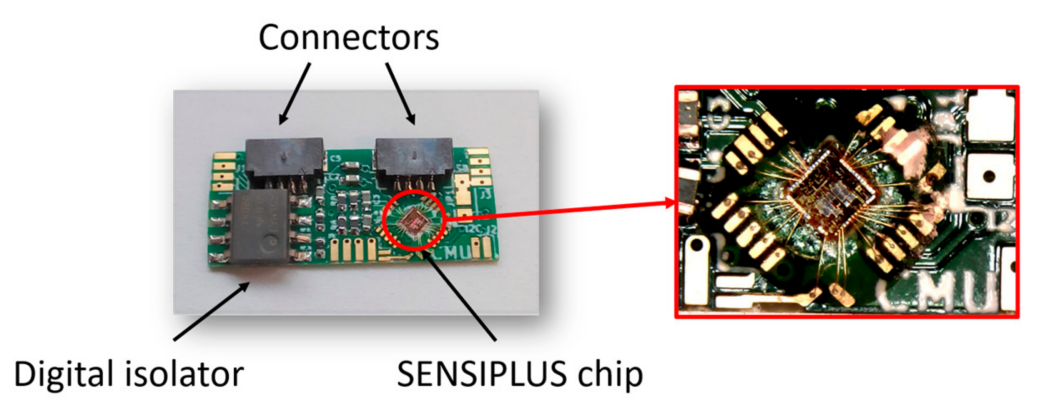

Figure 3. CMU board with the main components indicated and a magnified view of the SENSIPLUS chip.

The digital isolator (Texas Instrument ISO1640-Q1) has four input and four output terminals: two pairs are dedicated to the supply voltage and ground of each side (CMU and bus), while the other two are used for data transmission. The isolator has been used to guarantee a galvanic isolation between the individual battery electrical domains $\left(\right.$ gnd $\left._{\mathrm{H}}-\mathrm{V}_{\text {batt }} ; 0-4.2 \mathrm{~V}\right)$ and the bus/microcontroller one $\left(\mathrm{gnd}_{\mathrm{L}}-\mathrm{V}_{\mathrm{L}} ; 0-3.3 \mathrm{~V}\right)$. Isolated data transmission is clearly necessary in battery packs consisting of several series connected cells, where large voltage differences are present between the ground connections (negative terminals of the cells) of the individual CMUs that share the same communication bus.

The two connectors, visible on the top side of Figure 3, are used to connect the CMU to the host microcontroller by means of the $\mathrm{I}^{2} \mathrm{C}$ or SENSIBUS protocol. In a single cell scenario, only one connector is used, while both connectors are necessary for multi-cell application in order to obtain a daisy chain configuration.

SENSIPLUS is a versatile System on a Chip (SoC) for sensor interfacing, designed, and fabricated in a $0.18 \mu \mathrm{m}$ CMOS process. A simplified block diagram of the SENSIPLUS chip is shown in Figure 4. SENSIPLUS is designed to accomplish the widest range of measurements that can be performed on physical and chemical systems. Stimulation is provided by two main blocks: the Stimuli Synthesizer (SSy) and the Trans Impedance Amplifier (TIA). The former produces sinusoidal waveforms across a relatively large frequency interval $(40 \mathrm{~Hz}-1 \mathrm{MHz})$. The waveform is applied to the force terminal (SF), while the sense terminal (SS) optionally can be used to close the feedback directly on the DUT to be stimulated, avoiding the effects of series resistances. The SSy can be configured to produce an output voltage (up to a rail-to-rail magnitude) or an output current (up to $30 \mathrm{~mA}$ peak-to-peak). A DC bias, controllable with 12 bit resolution, can be superimposed on the sinusoidal waveform. The TIA applies a DC voltage (programmable with 6 bit resolution) to the force terminal (TF) and reads the current entering the terminal itself. A voltage proportional to the input current is presented across terminals $V_{R p}$ and $V_{R n}$. As for the SSy, the possibility to close the feedback on the sensor is enabled by a sense terminal (TS). Voltage references to all analog blocks is provided by a programmable differential Band-Gap Voltage Reference (VR) unit [29].

A programmable-gain Instrumentation Amplifier (In-Amp) is used to either read the voltage $V_{R p}-V_{R n}$, encoding the TIA current, or directly read a voltage on the selected sensor, according to the state of the In-Amp MUX (analog multiplexer). The In-Amp is based on the topology described in [30] and it has four different available gains: 1, 10, 20, and 50. The Flexible Terminal Configurator (FTC) is a complex analog mux that connects the four wires indicated as SP (Sensor Probe) in Figure 4 to several different selections of the SSy and TIA force/sense terminals and In-Amp inputs. By proper configuration of the FTC, it is possible to perform different types of measurements, such as two-wire and four wire impedance, differential voltage, and current measurements. The four SP terminals can be routed to different sensors through the Main-Mux. External sensors can be connected to ports $\mathrm{P} 0-\mathrm{P} 3$, each one including the complete 4 wire set. The chip also 
includes internal sensors: a temperature reading is derived from the VR block, while the analog power supply voltage $\left(\mathrm{V}_{\mathrm{dd}}\right)$ can be read through a 1:3 voltage diver. Additionally, the impedance of fingered electrode arrays fabricated on the chip surface can be read to perform humidity measurements and detection of dangerous gases (not used in this work) [31,32]. The In-Amp is coupled with an input and output modulator (switch matrix) that can be configured to perform chopper modulation for low-noise, low-offset DC measurements, and in-phase/quadrature demodulation, for impedance vector analysis. The DC component produced by the In-Amp is acquired by a delta-sigma ADC producing a BitStream (BS out) that is filtered and converted to a 20 bit digital word by the Digital Sub-Unit (DSU), also integrated into the SENSIPLUS chip. The DSU is a complex state machine that controls all the analog blocks described so far, generating the required clock signals and the digital configuration parameters (data). The DSU communicates with an external host by means of a digital communication line that can be programmed to implement standard protocols $\left(\mathrm{I}^{2} \mathrm{C}\right.$ and SPI) and the proprietary SENSIBUS protocol.

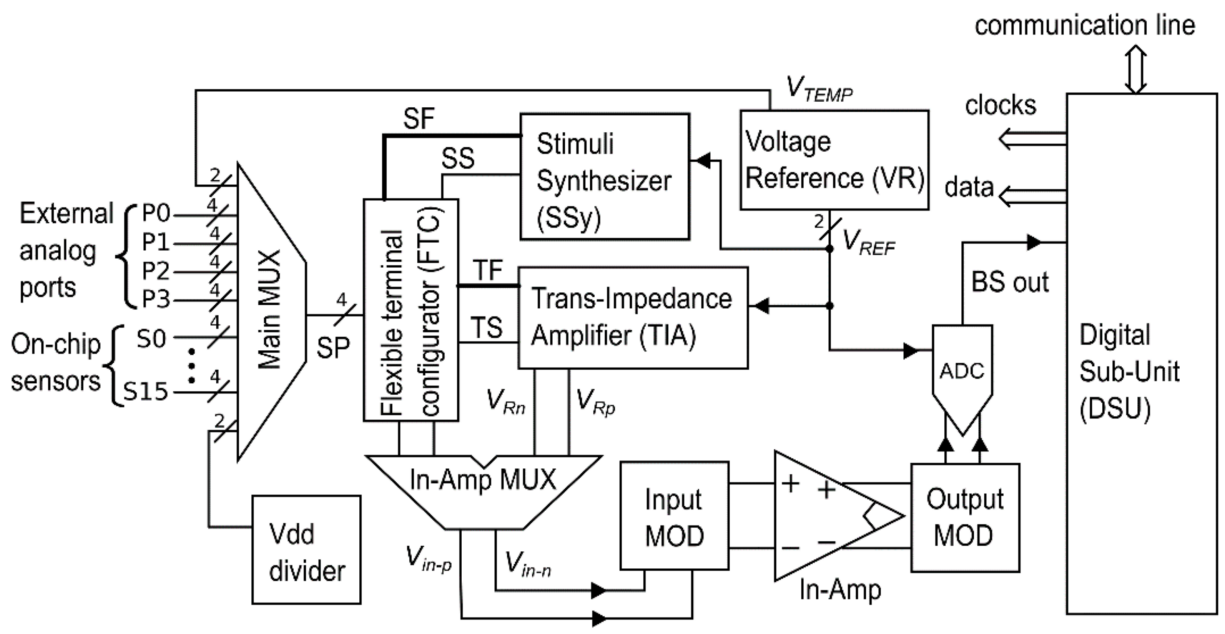

Figure 4. Simplified block diagram of the SENSIPLUS chip.

As it is possible to see in Figure 1B, the PCB contains a Wheatstone bridge, formed by four resistors and two capacitors of $1 \mathrm{M} \Omega$ and $1 \mu \mathrm{F}$, respectively. They allow the chip to measure the internal battery impedance. The schematic view of Figure 5 illustrates the method used to perform this measurement, which is of primary importance for monitoring the SoH of the cell. The cell is stimulated by the current source producing a constant DC value $\left(\mathrm{I}_{0}\right)$ and a sinusoidal component. The DC current component is required to guarantee that the imposed current does not change direction during the whole period of the sinusoidal component. The Wheatstone bridge transmits a virtually zero differential $D C$ voltage to the In-Amp, with a common mode voltage close to $V_{d d} / 2$. In this way the In-Amp is correctly biased and can be configured for maximum gain ( $34 \mathrm{~dB}$ ) with no risk of output saturation. The small AC variation of the cell voltage caused by the sinusoidal component of the current source is transmitted to the In-Amp input without attenuation, thanks to the unbalancing capacitors ( $\mathrm{C}$ in the figure), as far as the frequency is much higher than the cut-off value $f_{c}=(2 \pi R C)^{-1}=0.16 \mathrm{~Hz}$. The In-Amp and current source are implemented by means of the blocks integrated into the SENSIPLUS. In-phase and quadrature demodulation of the voltage read by the In-Amp allow estimation of the cell internal impedance. The current source is implemented by block SSy (see Figure 4) and its DC value, AC magnitude, and AC frequency are widely programmable. The SENSIPLUS is connected to the cell and Wheatstone bridge through terminals of port P0. 


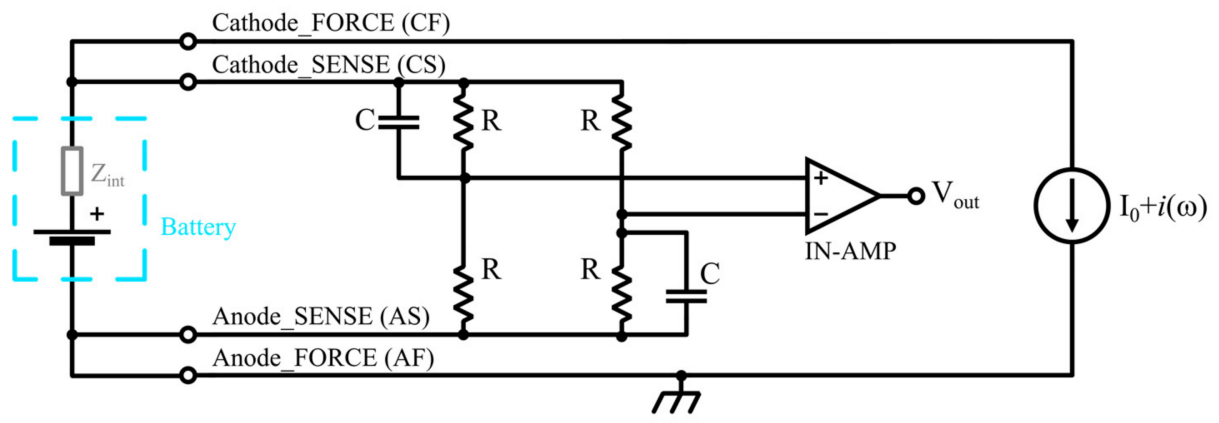

Figure 5. Arrangement used for internal battery impedance measurement.

\subsection{External Sensor Description}

The external sensors have been applied to the electrodes (EES) or to the cell body (EBS).

The EBS, as shown in Figure 6, consists of a commercial Negative Temperature Coefficient (NTC) resistor (Panasonic ERT-JZEV104F) and a custom comb finger capacitor used to sense the presence of moisture. This capacitor is fabricated with a standard flexible PCB process where the copper fingers are covered by a Kapton layer in order to prevent unwanted short circuits. The Kapton flexible board $\left(30 \times 20 \mathrm{~mm}^{2}\right)$ is glued to the external body of the cell.



A)

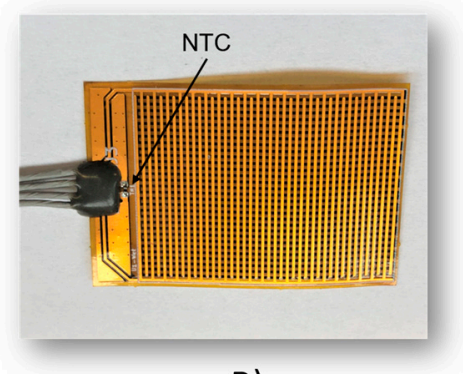

B)

Figure 6. External Body Sensor (EBS). (A) Schematic representation and (B) photograph.

Two EESs are used in our CMU applications: one is soldered to the cathode and the other to the anode. The schematic view and the photo of one EES is shown in Figure 7. It is a $10 \times 5 \mathrm{~mm}^{2}$ flexible board plated with gold and equipped with four leads. The two central leads $\left(\mathrm{NTC}_{1}\right.$ and $\mathrm{NTC}_{2}$ ) are used to connect the NTC sensor soldered on the board. In this way, the temperature of the individual electrodes can be acquired. The other two leads (AF-AS for the anode and CF-CS for the cathode) connect the electrodes of the cell to the CMU as shown in Figure 5. In particular, AF-CF provide the supply voltage to the $\mathrm{CMU}$ electronic circuits and are used to apply the stimulus current signal generated by the internal current generator. The AS-CS leads connect the Wheatstone bridge to the cell (voltage sensing terminals).

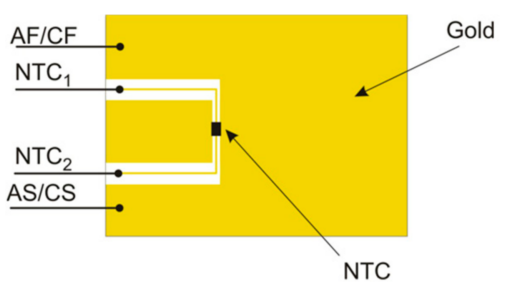

A)

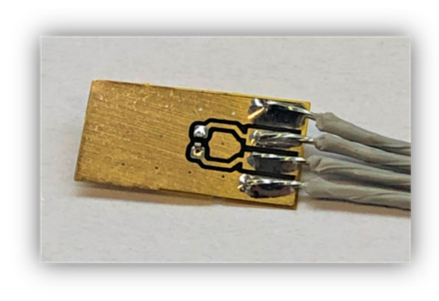

B)

Figure 7. External Electrode Sensor (EES). (A) Schematic representation and (B) photograph. 


\section{Measurements and Results}

The CMU characterization has been performed with the experimental setup shown in Figure 8. Software developed by SENSICHIPS s.r.l. (Via delle Valli 46, 04011 Aprilia (LT)Italy) in cooperation with the University of Cassino (Italy), based on the JAVA language, has been used to control all the CMU function and collect the output data. This piece of software is compatible with either Microsoft Windows operating system (through a JAVA virtual machine) and natively with Android-based systems. In this work, a PC was used to run the software and automate all measurements. The microcontroller board is a D1 Mini NodeMCU ESP32 of AZDelivery, which convert the USB computer output into one of the protocols supported by the SENSIPLUS chip. Due to the simple purpose of the microcontroller board, solutions based on different commercial components can be used with full compatibility.

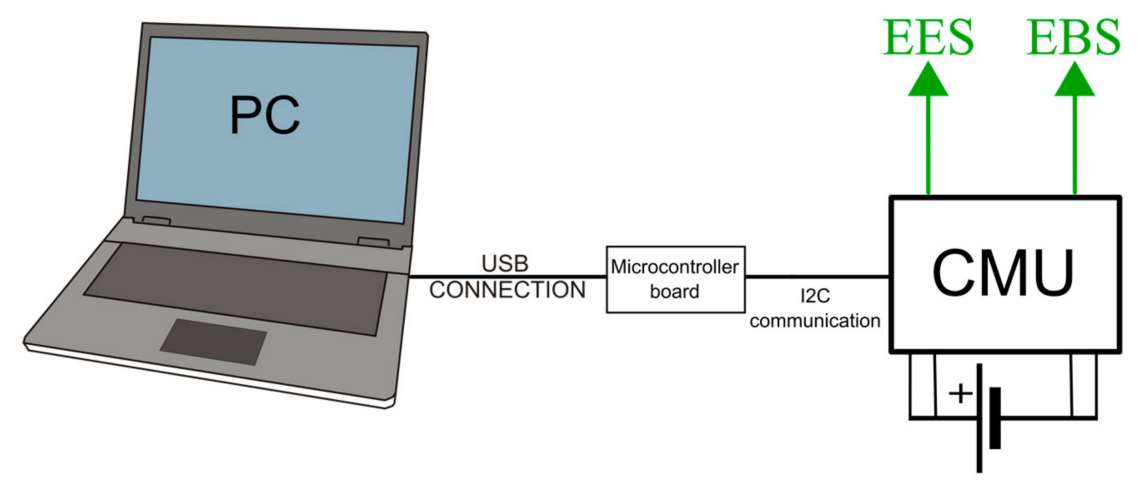

Figure 8. Complete measurement system.

The battery under test is a 3.7 V, 12,500 mAh LiPo cell. A standard Protection Circuit Module (PCM) is present on the battery in order to protect the cell from short circuit, overvoltage, and undervoltage. Measurements performed with and without the PCM showed no significant differences. For this reason, the PCM has been removed from our characterization measures preventing any possible interference.

\subsection{CMU Characterization}

In the proposed configuration, the CMU allows three different measurements: (i) chip temperature, (ii) cell voltage, and (iii) battery impedance spectrum (EIS).

The chip temperature measurements were performed by placing the CMU on a metal plate whose temperature was controlled by means of a Peltier cryostat. The temperature was swept with $10^{\circ} \mathrm{C}$ steps from 5 to $85^{\circ} \mathrm{C}$. In this way, we have tested the capability of the CMU to measure the temperature of the battery body at the location where the CMU is placed. The $\mathrm{V}_{\text {TEMP }}$ signal (see Figure 4) has been converted in temperature values by the software using a simple linear relationship, based on nominal parameters estimated by electrical simulations of the SENSIPLUS chip. In Figure 9 we compare the temperature measured by the CMU $\left(T_{\text {meas }}\right)$ with the one applied by the cryostat $\left(T_{\text {set }}\right)$. The linear fitting gives the following relationship:

$$
T_{\text {meas }}=1.00036 \cdot T_{\text {set }}-0.00784\left[{ }^{\circ} \mathrm{C}\right] \text {. }
$$

The very small slope and offset errors suggest that the temperature can be accurately measured by the CMU with no need of individual calibration. An equivalent temperature rms noise of $0.016^{\circ} \mathrm{C}$ was estimated from repeated measurements. 


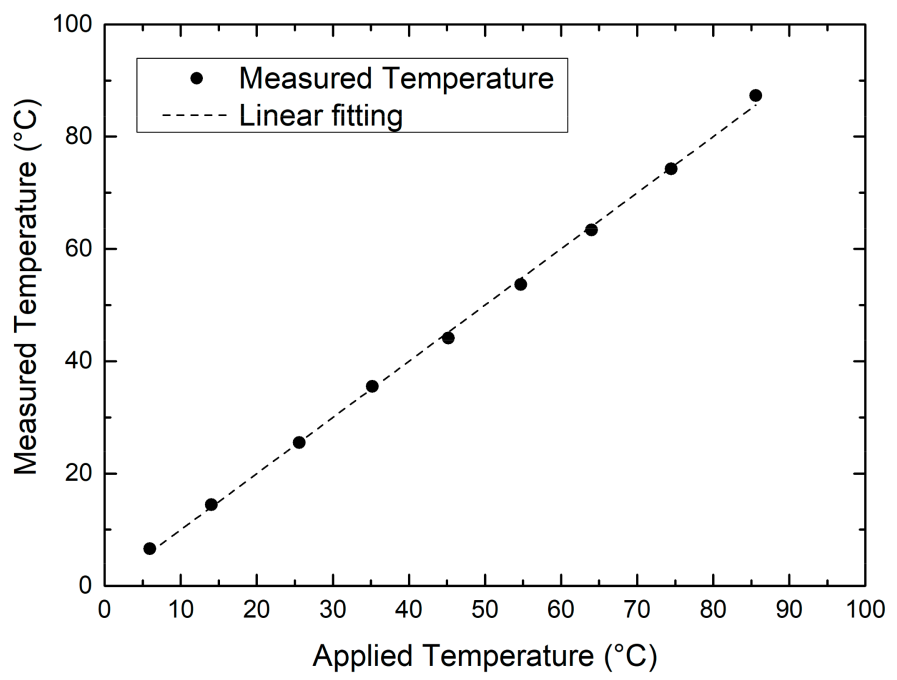

Figure 9. CMU measured temperature vs. cryostat applied temperature.

The cell voltage measurement was performed by exploiting the internal $V_{\mathrm{dd}}$ divider of the SENSIPLUS chip (see Figure 4). Note that in the used configuration, the SENSIPLUS supply voltage coincides with the cell voltage (see Figure 1). Different cell voltages were simulated by using a computer-controlled power supply (Agilent E3646A, Santa Clara, CA, USA): the supply voltage was swept from 2.6 to $4.5 \mathrm{~V}$ and the measurements performed by the CMU were recorded. The lower limit of the sweep was determined by the minimum voltage at which the digital isolator was found to operate correctly. The upper limit was imposed by the maximum ratings of the CMOS process used to fabricate the SENSIPLUS chip. The measurements performed by $\mathrm{CMU}\left(V_{d d-\text { meas }}\right)$ are plotted in Figure 10 as a function of the applied supply voltage $\left(V_{d d}\right)$ measured by a digital multimeter (Agilent $344110 \mathrm{~A}$ ).

The linear fit, shown by the dashed line in Figure 10, is represented by the following equation:

$$
V_{d d-\text { meas }}=1.00182 \cdot V_{d d}+0.02237[\mathrm{~V}] .
$$

A slope error less than $0.2 \%$ and a $22 \mathrm{mV}$ offset error can be estimated from these uncalibrated data. A rms noise of nearly $80 \mu \mathrm{V}$ was calculated from repeated measurements.

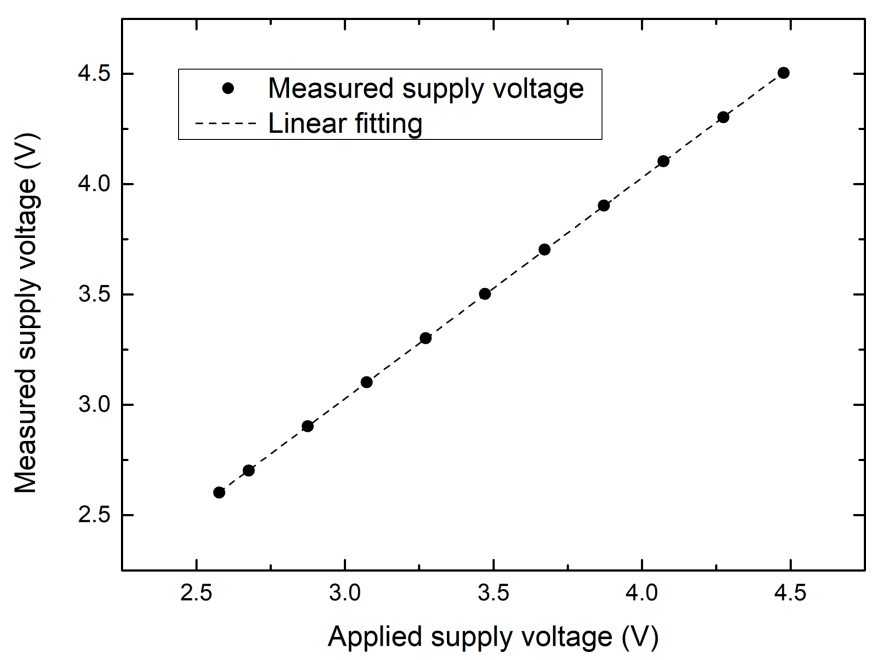

Figure 10. CMU measured supply voltage vs. applied supply voltage.

For the internal battery impedance, two different sets of measurements were performed. The first one was made to confirm the correct operation of the setup and to calibrate the impedance measurement. The second one was performed to obtain the Nyquist plot of the cell under test. In the calibration phase, four different resistors were 
incrementally inserted in series to the battery. In this way the battery impedance was artificially increased by a resistance varying from 20 to $50 \mathrm{~m} \Omega$ in steps of $10 \mathrm{~m} \Omega$. The additional resistors were soldered to avoid any contribution from contact resistances. The measurement was performed by stimulating the battery with a sinusoidal current having a $30 \mathrm{~mA}$ peak-to-peak magnitude and $15 \mathrm{~mA}$ DC value. The raw output code produced by the ADC for a stimulus frequency of $200 \mathrm{~Hz}$ is shown in Figure 11 for the mentioned four resistance values. Correct operation is proved by the excellent linear behavior.

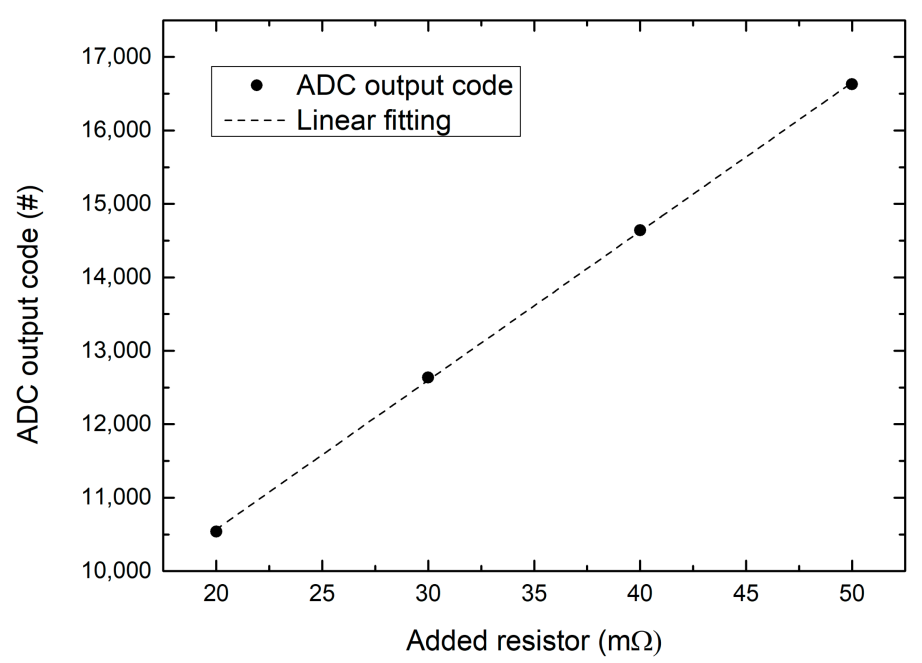

Figure 11. Code obtained from the CMU ADC for different additional resistances.

From the measurements shown in Figure 11, the parameters of the linear relationship used to convert the ADC data into resistance and reactance values have been calculated. The resolution of the resistance measurement, estimated at $1 \mathrm{kHz}$ from the equivalent resistance noise, was nearly $120 \mu \Omega$. In the literature, there are very few examples of similar miniaturized vector impedance analyzer based on a single chip architecture [22,23]. In particular, a resolution of $74 \mathrm{~m} \Omega @ 1 \mathrm{kHz}$ is provided in [23], while in [22], no resolution and accuracy data are available. After calibration, the real EIS measurements were performed on the cell under test. The stimulus frequency was swept from $40 \mathrm{~Hz}$ to $5 \mathrm{kHz}$. The results are shown in Figure 12 where a consistent battery Nyquist plot is visible. The minimum frequency of the sweep was due to limitations of the present version of the SENSIPLUS Stimuli Synthesizer.

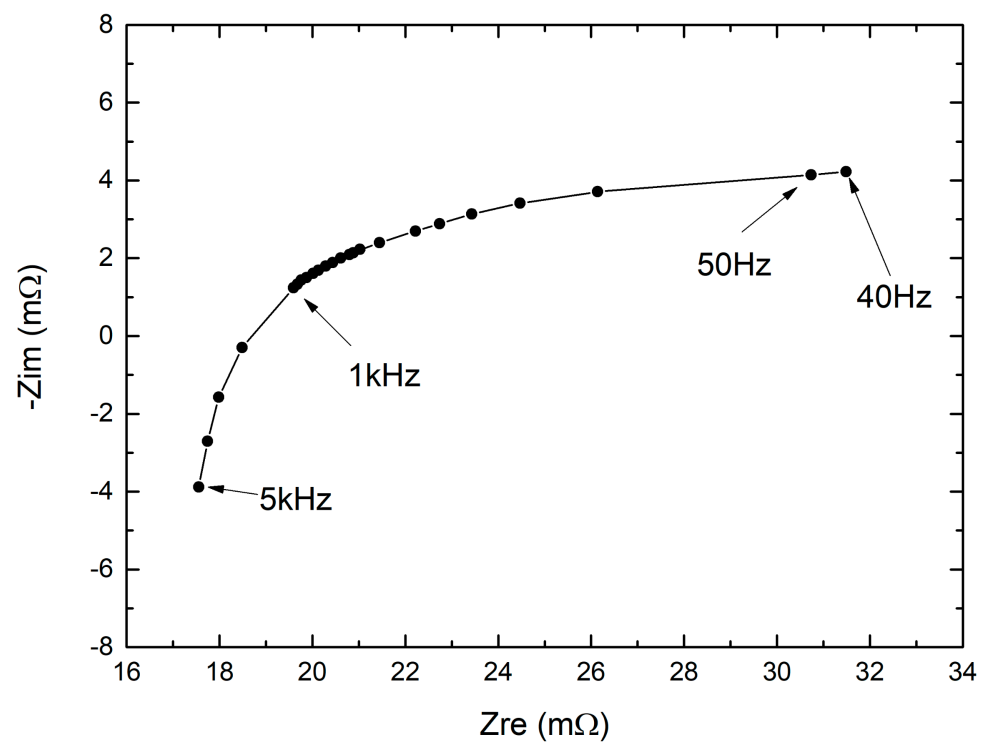

Figure 12. Nyquist cell plot from $40 \mathrm{~Hz}$ to $5 \mathrm{kHz}$. 


\subsection{External Sensor Characterization}

Two different external sensors have been connected to the CMU to demonstrate the capability of the SENSIPLUS chip to measure multiple physical parameters.

A commercial NTC sensor (Panasonic ERT-JZEV104F, OSAKA, Japan), mounted into the EES board (Figure 7), has been connected to an external analog port of the SENSIPLUS chip. The EES has been fixed to the metal plate of the cryostat by means of thermal paste. Figure 13 shows the value of the measured resistance $(R)$ as a function of temperature $(T)$. Considering the log-Y scale, a good linearity is clearly visible, and the curve behavior confirms with the NTC datasheet characteristics.

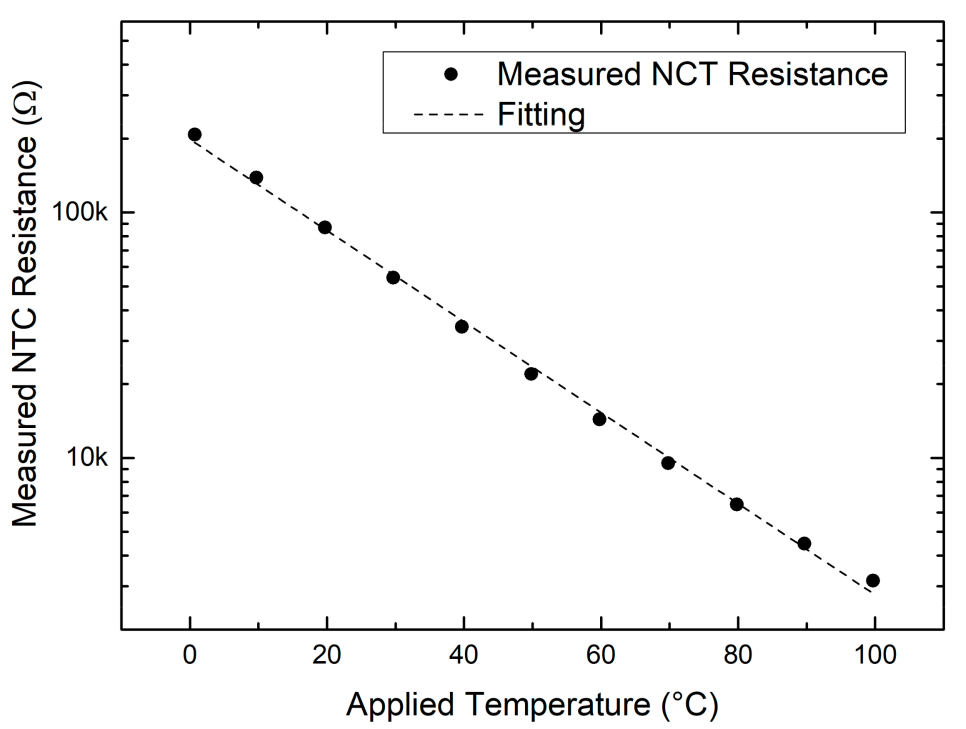

Figure 13. CMU measured NTC resistance vs. cryostat applied temperature.

As the moisture sensor is concerned, the EBS board was glued on a plexiglass support with a graduated ruler on a side. This support was connected to a manual operated vertical displacement stage and placed inside a beaker. The complete setup is shown in Figure 14.

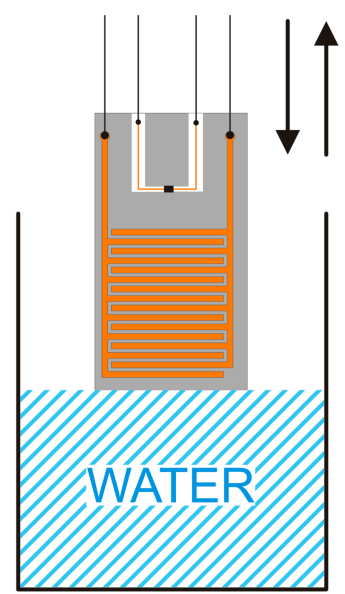

Figure 14. Setup for level sensor characterization.

To obtain a capacitance vs. $\mathrm{H}_{2} \mathrm{O}$ level trend, the beaker was initially filled with water up to the bottom side of the EBS. The board was then gradually immersed in the water and the capacitance was measured for a set of displacements. The obtained characteristic is shown in Figure 15. 


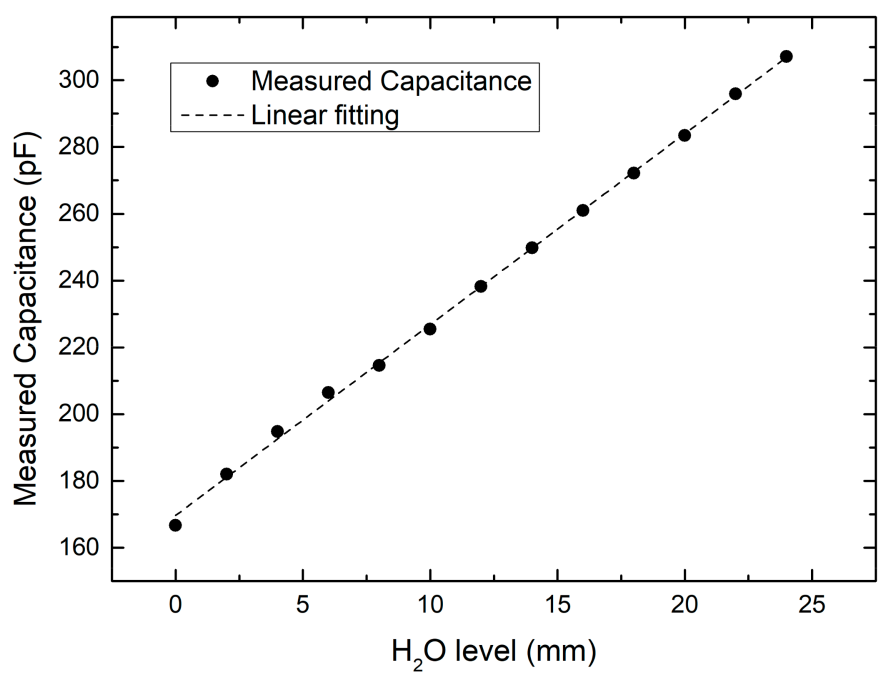

Figure 15. Moisture sensor measured capacitance vs. $\mathrm{H}_{2} \mathrm{O}$ level.

After a linear fitting analysis, we obtain:

$$
C=5.7 \cdot d+169[\mathrm{pF}],
$$

with $C$ the capacitance in $\mathrm{pF}$ and $d$ the displacement in millimeter.

The observed linear behavior confirms the intuitive predictions that the capacitance increase should be proportional to the fraction of sensor wet surface. It is worth noting that such a sensor could be used also for detecting possible electrolyte spillage.

\section{Conclusions}

Experiments performed on the proposed CMU demonstrated the ability to acquire several parameters related to safety conditions (temperature, presence of moisture) and to $\mathrm{SoH}$ (temperature, output voltage, internal cell impedance) of Lithium-Ion Cells. Voltage ratings of the proposed device are compatible with voltage levels of a single cell. Nevertheless, the flexibility of the communication interface and the use of a digital isolator allows connecting several battery cells in series while sharing two wires $\left(\mathrm{I}^{2} \mathrm{C}\right)$ or single wire (SENSIBUS) protocols. In this way, monitoring of all the cells present in series-connected battery pack can be significantly simplified with respect to a centralized BMS. The measurement set-up described in the previous section was conceived to show the flexibility of the system. Multi-point temperature readings, obtained from thermistors integrated in the cell anode and cathode tabs and from the accurate sensor embedded in the SENSIPLUS chip, are combined with a custom moisture sensor built by using a commercial flexible PCB technology. Different sensor configuration, capable of meeting a wide range of battery monitoring requirements, are possible, thanks to the large number of configurable analog ports of the SENSIBUS, enabling up to four four-wire and eight two-wire independent measurements. Four-wire measurements of the output cell impedance required only a small set of external passive components and were performed while the CMU is powered by the same battery under test, obtaining excellent linearity and a resolution of $120 \mu \Omega$. The lower frequency limit of the EIS measurements $(40 \mathrm{~Hz})$ are not due to physical limitation of the analog SENSIPLUS interface and will be easily overcome in future versions by updating the digital sub-unit.

Author Contributions: All authors participated to the conceptualization and methodology of this work. Software, M.M., L.G., and M.V.; investigation, G.M. and A.R.; data curation, G.M., A.R., and M.P.; writing—original draft preparation, G.M., A.R., P.B., and M.P.; writing—review and editing, P.B. and M.P.; visualization, G.M. and A.R. All authors have read and agreed to the published version of the manuscript. 
Funding: This research was funded by the EU H2020 project 3beLiEVe, grant agreement number 875033.

Conflicts of Interest: The authors declare no conflict of interest.

\section{References}

1. Goodenough, J.B.; Park, K.S. The Li-ion rechargeable battery: A perspective. J. Am. Chem. Soc. 2013, 135, 1167-1176. [CrossRef]

2. Blomgren, G.E. The development and future of lithium ion batteries. J. Electrochem. Soc. 2016, 164, A5019. [CrossRef]

3. Wu, F.; Maier, J.; Yu, Y. Guidelines and trends for next-generation rechargeable lithium and lithium-ion batteries. Chem. Soc. Rev. 2020, 49, 1569-1614. [CrossRef]

4. Dunn, B.; Kamath, H.; Tarascon, J.M. Electrical energy storage for the grid: A battery of choices. Science 2011, 334, 928-935. [CrossRef]

5. Armand, M.; Tarascon, J.M. Building better batteries. Nature 2008, 451, 652-657. [CrossRef] [PubMed]

6. Chen, Y.; Kang, Y.; Zhao, Y.; Wang, L.; Liu, J.; Li, Y.; Liang, Z.; He, X.; Li, X.; Tavajohi, N.; et al. A review of lithium-ion battery safety concerns: The issues, strategies, and testing standards. J. Energy Chem. 2020. [CrossRef]

7. Waag, W.; Fleischer, C.; Sauer, D.U. Critical review of the methods for monitoring of lithium-ion batteries in electric and hybrid vehicles. J. Power Sources 2014, 258, 321-339. [CrossRef]

8. Berecibar, M.; Gandiaga, I.; Villarreal, I.; Omar, N.; Van Mierlo, J.; Van den Bossche, P. Critical review of state of health estimation methods of Li-ion batteries for real applications. Renew. Sustain. Energy Rev. 2016, 56, 572-587. [CrossRef]

9. Park, S.; Ahn, J.; Kang, T.; Park, S.; Kim, Y.; Cho, I.; Kim, J. Review of state-of-the-art battery state estimation technologies for battery management systems of stationary energy storage systems. J. Power Electron. 2020, 1-15. [CrossRef]

10. Wang, Y.; Tian, J.; Sun, Z.; Wang, L.; Xu, R.; Li, M.; Chen, Z. A comprehensive review of battery modeling and state estimation approaches for advanced battery management systems. Renew. Sustain. Energy Rev. 2020, 131, 110015. [CrossRef]

11. Kim, C.H.; Kim, M.Y.; Moon, G.W. A modularized charge equalizer using a battery monitoring IC for series-connected Li-ion battery strings in electric vehicles. IEEE Trans. Power Electron. 2012, 28, 3779-3787. [CrossRef]

12. Dai, H.; Jiang, B.; Hu, X.; Lin, X.; Wei, X.; Pecht, M. Advanced battery management strategies for a sustainable energy future: Multilayer design concepts and research trends. Renew. Sustain. Energy Rev. 2020, 110480. [CrossRef]

13. Steinhorst, S.; Lukasiewycz, M.; Narayanaswamy, S.; Kauer, M.; Chakraborty, S. Smart cells for embedded battery management. In Proceedings of the 2014 IEEE International Conference on Cyber-Physical Systems, Networks, and Applications, Hong Kong, China, 25-26 August 2014; pp. 59-64. [CrossRef]

14. Berecibar, M. Accurate predictions of lithium-ion battery life. Nature 2019, 568, 325-326. [CrossRef] [PubMed]

15. Wei, Z.; Zhao, J.; He, H.; Ding, G.; Cui, H.; Liu, L. Future smart battery and management: Advanced sensing from external to embedded multi-dimensional measurement. J. Power Sources 2021, 489, 229462. [CrossRef]

16. Available online: https:/ / sensichips.com (accessed on 29 June 2021).

17. Osaka, T.; Mukoyama, D.; Nara, H. Development of diagnostic process for commercially available batteries, especially lithium ion battery, by electrochemical impedance spectroscopy. J. Electrochem. Soc. 2015, 162, A2529. [CrossRef]

18. Choi, W.; Shin, H.C.; Kim, J.M.; Choi, J.Y.; Yoon, W.S. Modeling and applications of electrochemical impedance spectroscopy (EIS) for lithium-ion batteries. J. Electrochem. Sci. Technol. 2020, 11, 1-13. [CrossRef]

19. Wang, L.F.; Geng, M.M.; Ding, X.N.; Fang, C.; Zhang, Y.; Shi, S.S.; Zheng, Y.; Yang, K.; Zhan, C.; Wang, X.D. Research progress of the electrochemical impedance technique applied to the high-capacity lithium-ion battery. Int. J. Miner. Metall. Mater. 2021, 28, 538-552. [CrossRef]

20. Islam, S.M.R.; Park, S.-Y.; Balasingam, B. Unification of Internal Resistance Estimation Methods for Li-Ion Batteries Using Hysteresis-Free Equivalent Circuit Models. Batteries 2020, 6, 32. [CrossRef]

21. Kehl, D.; Jennert, T.; Lienesch, F.; Kurrat, M. Electrical Characterization of Li-Ion Battery Modules for Second-Life Applications. Batteries 2021, 7, 32. [CrossRef]

22. Varnosfaderani, M.A.; Strickland, D. A comparison of online electrochemical spectroscopy impedance estimation of batteries. IEEE Access 2018, 6, 23668-23677. [CrossRef]

23. Huang, W.; Qahouq, J.A.A. An online battery impedance measurement method using DC-DC power converter control. IEEE Trans. Ind. Electron. 2014, 61, 5987-5995. [CrossRef]

24. Varnosfaderani, M.A.; Strickland, D. Online impedance spectroscopy estimation of a dc-dc converter connected battery using a switched capacitor-based balancing circuit. J. Eng. 2019, 2019, 4681-4685. [CrossRef]

25. Gong, Z.; Liu, Z.; Wang, Y.; Gupta, K.; Da Silva, C.; Liu, T.; Zheng, Z.H.; Zhang, W.P.; van Lammeren, J.M.; Bergveld, H.J.; et al. IC for online EIS in automotive batteries and hybrid architecture for high-current perturbation in low-impedance cells. In Proceedings of the 2018 IEEE Applied Power Electronics Conference and Exposition (APEC), San Antonio, TX, USA, 4-8 March 2018; pp. 1922-1929. [CrossRef]

26. Crescentini, M.; De Angelis, A.; Ramilli, R.; De Angelis, G.; Tartagni, M.; Moschitta, A.; Traverso, P.A.; Carbone, P. Online EIS and diagnostics on lithium-ion batteries by means of low-power integrated sensing and parametric modeling. IEEE Trans. Instrum. Meas. 2020, 70, 1-11. [CrossRef]

27. Rehman, S.; Khan, K.; Zhao, Y.; Hou, Y. Nanostructured cathode materials for lithium-sulfur batteries: Progress, challenges and perspectives. J. Mater. Chem. A 2017, 5, 3014-3038. [CrossRef]

28. Wen, G.; Rehman, S.; Tranter, T.G.; Ghosh, D.; Chen, Z.; Gostick, J.T.; Pope, M.A. Insights into Multiphase Reactions during Self-Discharge of Li-S Batteries. Chem. Mater. 2020, 32, 4518-4526. [CrossRef] 
29. Del Cesta, S.; Ria, A.; Simmarano, R.; Piotto, M.; Bruschi, P. A compact programmable differential voltage reference with unbuffered $4 \mathrm{~mA}$ output current capability and $\pm 0.4 \%$ untrimmed spread. In Proceedings of the ESSCIRC 2017-43rd IEEE European Solid State Circuits Conference, Leuven, Belgium, 1-14 September 2017; pp. 11-14. [CrossRef]

30. Del Cesta, S.; Ria, A.; Piotto, M.; Simmarano, R.; Bruschi, P. A compact current-mode instrumentation amplifier for generalpurpose sensor interfaces. AEU Int. J. Electron. Commun. 2018, 8-14. [CrossRef]

31. Bruschi, P.; Cerro, G.; Colace, L.; De Iacovo, A.; Del Cesta, S.; Ferdinandi, M.; Ferrigno, L.; Molinara, M.; Ria, A.; Simmarano, R.; et al. A novel integrated smart system for indoor air monitoring and gas recognition. In Proceedings of the 2018 IEEE International Conference on Smart Computing (SMARTCOMP), Taormina, Italy, 18-20 June 2018; pp. 470-475. [CrossRef]

32. Molinara, M.; Ferdinandi, M.; Cerro, G.; Ferrigno, L.; Massera, E. An End to End Indoor Air Monitoring System Based on Machine Learning and SENSIPLUS Platform. IEEE Access 2020, 72204-72215. [CrossRef] 